\title{
Evolución de los parámetros del enfoque integrado en las políticas de regeneración urbana en los barrios vulnerables en España
}

\section{Evolution of the parameters of the integrated approach in urban regeneration policies in vulnerable neighborhoods in Spain}

\author{
Ángela Matesanz Parellada \\ École National des Travaux Publiques de l'Etat (ENTPE) \\ angela.matesanz@upm.es
}

\section{NOTA BIOGRÁFICA}

Doctora Arquitecta por la Escuela Técnica Superior de Arquitectura de Madrid (ETSAM) de la Universidad Politécnica de Madrid (UPM) en 2017, con Políticas urbanas y vulnerabilidad, y Máster en Planeamiento Urbano y Territorial (DUyOT-UPM) en 2011. Desde 2005 ha participado en múltiples investigaciones sobre Vulnerabilidad urbana y Regeneración y Rehabilitación urbanas tanto con la UPM como con otras universidades.

Agustín Hernández Aja

Universidad Politécnica de Madrid (UPM) agustin.hernandez@upm.es

\section{NOTA BIOGRÁFICA}

Doctor arquitecto, delegado del rector de la UPM en materia de «Urbanismo, Sostenibilidad y Movilidad Intercampus» y director del Grupo de Investigación en Arquitectura, Urbanismo y Sostenibilidad. Ha dirigido trabajos dirigidos a la detección de Barrios Vulnerables en 1991, 2001 y 2011, incluidos en el Observatorio de la Vulnerabilidad Urbana, así como proyectos sobre rehabilitación y regeneración urbana.

\section{RESUMEN}

El desarrollo en el tiempo de políticas urbanas basadas en un enfoque integrado y dirigidas a la regeneración de barrios considerados desfavorecidos en el marco europeo ha influido en el contexto español (De Gregorio, 2012; González, 2011), que, sin embargo, ha tenido una evolución y características propias, tanto en el marco legislativo y administrativo, como en la práctica urbanística (Matesanz y Hernández, 2014). Este artículo busca analizar la evolución de los parámetros ligados al enfoque integrado (integración de las áreas, de los agentes e integración en la ciudad) en el discurso jurídico-administrativo de las políticas urbanas dirigidas a «regenerar» la ciudad consolidada en España, especialmente en barrios vulnerables. Como resultado de este análisis se observan variaciones, no sólo en la intensidad de la integración propuesta en sus planes y programas, sino en sus planteamientos y objetivos, inseparables del tipo de actuación proyectada y modelo de ciudad vinculado a ella.

\section{PALABRAS CLAVE}

Rehabilitación urbana; integralidad; vulnerabilidad urbana; pobreza urbana. 


\begin{abstract}
The long-lasting development of urban policies based on an integrated approach and aimed at disadvantaged neighborhoods' regeneration in the European framework has largely influenced the Spanish context (De Gregorio, 2012; González, 2011). However, the Spanish context has had its own evolution and characteristics, both in urban practice as in the legislative and administrative framework (Matesanz and Hernández, 2014). The present article seeks to analyze the evolution of the parameters linked to the integrated approach (areas, agents and urban integration) in the legal-administrative discourse of urban policies aimed at «regenerating» the consolidated city in Spain, especially the vulnerable neighborhoods. As a result of this analysis, variations are observed, not only in the intensity of the integration proposed in their plans and programs, but also in their approaches and objectives, inseparable from the type of projected performance and city model linked to it.
\end{abstract}

\title{
KEYWORDS
}

Urban rehabilitation; comprehensiveness; urban vulnerability; urban poverty.

\section{SUMARIO}

INTRODUCCIÓN. 1. METODOLOGÍA Y CUERPO DE ESTUDIO. 1.1. POLÍTICAS DE REGENERACIÓN URBANA: CUERPO DE ESTUDIO. 1.2. ENFOQUE INTEGRADO: MARCO DE ANÁLISIS. 1.3. ANÁLISIS DEL DISCURSO. 2. DE LA DECLARACIÓN AL PACTO DE ÁMSTERDAM (1975-2016). 2.1. LA REHABILITACIÓN INTEGRADA Y LA RECUPERACIÓN DE LA CIUDAD (1975-1992). Fase Experimental (19751979). Fase de consolidación de la Rehabilitación Integrada (1980-1985). Fase de transición de modelo (1985-1991). 2.2. REHABILITACIÓN URBANA Y EL DESARROLLO SOSTENIBLE (1992-2000). Fase de consolidación de la Rehabilitación Urbana (1992-1996). Fase inicial de la europeización y entrada del Desarrollo Sostenible (1996-2000). 2.3. LA REGENERACIÓN URBANA (2000- 2016). Fase de configuración de un nuevo tipo de intervención (2000-2006). Fase de declive y nueva transición (2007- 2016). 3. CONCLUSIONES: LA EVOLUCIÓN DE LOS PARÁMETROS DEL ENFOQUE INTEGRADO. 3.1. INTEGRACIÓN DE LAS ÁREAS. 3.2. INTEGRACIÓN DE LOS AGENTES. 3.3. INTEGRACIÓN EN LA CIUDAD. 3.4. LA EVOLUCIÓN DE LOS PARÁMETROS DEL ENFOQUE INTEGRADO. REFERENCIAS BIBLIOGRÁFICAS. 1. Legislación estatal analizada. 2. Documentos internacionales analizados.

\section{INTRODUCCIÓN}

Entre los doce temas prioritarios de la nueva Agenda Urbana de la Unión Europea (UE, 2016a), elaborada para asegurar el máximo potencial de las ciudades y afrontar con éxito los retos sociales, aparece la pobreza urbana. Este reto tiene por objetivo reducirla y permitir la inclusión de la población en riesgo de padecerla, en particular en los barrios desfavorecidos. Para ello apela a soluciones basadas en un enfoque integrado apoyado tanto en políticas horizontales (people-based), como territorializadas (place-based).

Si bien es cierto que la coexistencia y articulación de ambas políticas, horizontales y territorializadas, supone cierta novedad, la apuesta por la «Regeneración de los barrios desfavorecidos», incluida entre las cuatro prioridades del plan de acción, da continuidad a la línea desarrollada por la UE desde los años noventa, que se consolidó con la definición de la Regeneración Urbana Integrada (RUI), en la Declaración de Toledo de 2010.

En España estas ideas y su aplicación en forma de programas integrales dirigidos a barrios considerados desfavorecidos, han influido en las políticas desarrolladas desde las distintas administraciones (De Gregorio, 2012; González, 2011). Sin embargo, estas, bajo el amplio paraguas de la Rehabilitación urbana, se han distinguido por una evolución y características propias, marcadas por la hegemonía del sector inmobiliario en el desarrollo urbano, tanto en el marco legislativo y administrativo, como en la práctica urbanística (Matesanz y Hernández, 2014).

Este artículo parte de la hipótesis de que los parámetros ligados al enfoque integrado europeo han tenido presencia en el discurso de las políticas de rehabilitación de barrios en España entre 1975 y 2016, por lo tanto, antes de que se consolidara este término. Se plantea, además, que han variado su intensidad, enfoque e intención a lo largo del tiempo. La confirmación de esta hipótesis se apoya principalmente en el análisis de la evolución de dichos parámetros en el discurso del marco legislativo y administrativo estatal entre 1975 y 2016. 
Tras una breve mención a la metodología empleada, esta evolución se expone en el segundo apartado, estructurado en las etapas y fases de la rehabilitación urbana en España establecidas en el marco de la investigación (guiado por la figura 1). La descripción de cada una de ellas, iniciada con una breve mención al contexto internacional, identifica los parámetros relacionados con el enfoque integrado en el discurso administrativo estatal y lo relaciona con la practica real desarrollada en cada periodo. En el tercer apartado, a modo de conclusiones, se analiza brevemente la evolución para todo el periodo de cada uno de los parámetros de la RUI considerados: integración de las áreas temáticas, de los agentes y en la ciudad.

\section{METODOLOGÍA Y CUERPO DE ESTUDIO}

La Unión Europea definió la Regeneración Urbana Integrada (RUI) en 2010 como un «proceso planificado de intervención para la preservación/revalorización del capital urbano de un entorno construido y/o tejidos urbanos ya consolidados», prioritariamente dirigido a barrios desfavorecidos y basado en un enfoque integrado (Consejo de Ministros de la UE 2010:7). Esta definición, por un lado, establece el cuerpo de estudio de esta investigación, el de las políticas, planes y programas que se consideran incluidos en ese «proceso planificado» de regeneración. Por otro lado, fija la base de análisis, según la definición de los parámetros del enfoque integrado.

\subsection{Políticas de regeneración urbana: cuerpo de estudio}

La RUI, como proceso dirigido a «la ciudad consolidada» (UE, 2010), se enmarca tradicionalmente en España en las políticas rehabilitación urbana, articuladas desde el planeamiento y la vivienda.

Sin embargo, si atendemos a la complejidad de dichos procesos, estos marcos quedan superados. Desde el punto de vista jurídico, según argumenta María Jesús García (1999), se puede considerar que las intervenciones de rehabilitación tienen su fundamento jurídico en los principios rectores de la política social y económica enunciados por la Constitución, principalmente los relacionados con el patrimonio, la vivienda y uso del suelo y el medio ambiente (Constitución: Art. 46, Art.47, Art.45). Por otro lado, si consideramos el adjetivo Integrada, desde un punto de vista complejo, se superan las cuatro líneas anteriores y se vinculan además a otras políticas, planes y programas de naturaleza social y/o económica.

Esta consideración lleva a tomar como cuerpo de estudio las políticas urbanas ${ }^{1}$ de regeneración dirigidas desde estos ámbitos al tejido consolidado, representadas por sus textos legislativos y administrativos estatales de rango superior ${ }^{1}$. Además, la importancia del contexto internacional hace necesaria su relación con los textos que establecen el marco europeo ${ }^{2}$ y la fuerte vinculación con la práctica real determina la necesaria alusión a los procesos de rehabilitación urbana desarrollados bajo su amparo en España.

Se establece como periodo de estudio el comprendido entre mediados de los años setenta, momento en el que distintos autores sitúan los inicios de la rehabilitación urbana española (Amman, 1983; Castrillo, 2013) y en el que se aprobaron la Carta y la Declaración de Ámsterdam, y mediados de la segunda década del siglo XXI, en la que los programas europeos de intervención se han materializado en España en las Estrategias de Desarrollo Urbano Sostenible e Integrado (EDUSI) y se ha firmado el Pacto de Ámsterdam.

\subsection{Enfoque integrado: marco de análisis}

El enfoque integrado al que remiten la Agenda Urbana y el Pacto de Ámsterdam y al que queda vinculada la intervención en barrios a través de la RUI, podemos considerar que se define según la interpretación de la Declaración de Toledo por una triple dimensión:

- La integración de las áreas; parte del entendimiento de que los problemas que tienen los barrios en los que se desarrolla este tipo de intervenciones son complejos y de muy distinta naturaleza (social, económica, urbana, residencial...) y, por lo tanto, se precisa una respuesta que considere de forma conjunta todas estas cuestiones y sus interrelaciones desde una visión integral y articulada. No se reduce al desarrollo de distintas políticas de forma simultánea, en el mismo espacio y tiempo, si no que implica su coordinación, el aprovechamiento de las sinergias y la resolución de los conflic-

1 Entendidas según la definición de Blanco y Subirats (2012), a partir de una triple negación: no son sólo políticas urbanísticas, no son solo políticas municipales y no sólo políticas desarrolladas por la administración. 
tos derivados de la su puesta en marcha (Martí-Costa, Blanco y Pares, 2009).

- La integración de los agentes; relacionada con la gobernanza y la participación, responde a la búsqueda del diálogo entre los actores implicados, públicos y privados, y a su cooperación, tanto vertical (entre diferentes niveles de gobierno), como horizontal (entre distintas áreas de un mismo nivel de gobierno y entre los distintos actores).Parte de la idea de que el desarrollo de actuaciones integrales precisa un cambio substancial tanto en su funcionamiento como en la forma de trabajar (Martí-Costa, Blanco y Parés, 2009). .

- La Integración en la ciudad; llamada por algunos autores equilibrio intraurbano (Huete, Merinero, Muñoz, 2013) o integración externa (López y Tosics, 2010), se entiende por la relación de las zonas en las que se desarrollan los programas y la ciudad en su conjunto. Consolidada en los planteamientos de las EDUSI, ha sido la más marginalmente tratada hasta la fecha, siendo muy contadas las excepciones en las que se ha considerado esta escala, tanto en programas sociales como urbanísticos.

Este trabajo, que se enmarca en una investigación más amplia en torno a la relación entre la evolución del discurso y de la práctica de las políticas de regeneración urbana, toma la integración en la ciudad como punto de partida para el análisis ${ }^{2}$. Por ello, considera la integración de los agentes a través de la integración social y política en el total de la ciudad y la de las áreas temáticas a través de la articulación de las distintas funciones (de tipo social, económico, ambiental..etc) del barrio en su conjunto y con su entorno.

\subsection{Análisis del discurso}

El análisis del discurso implícito en el marco de la rehabilitación se basa en la propuesta cualitativa desarrollada por Atkinson, Held y Jeffares (2010). En él se entiende fundamental la identificación, por un lado, de los elementos que rodean dicho discurso (contexto económico, político y social, y teoría y cultura urbanística) (Van Dijk, 2005), y, por otro lado, del asunto del que tratan, los productos que generan -en forma de planes, programas o manuales-, y los agentes implicados, especialmente el emisor (Manzano, 2005).

La relación del marco teórico-jurídico con la práctica, se establece a partir del análisis de veinte casos de rehabilitación urbana en España ${ }^{3}$, estudiados en el trabajo «Análisis de las políticas estatales y europeas en materia de regeneración urbana y rehabilitación de barrios» desarrollado por un convenio entre el Ministerio de Vivienda y el Instituto Juan de Herrera del Departamento de Urbanística y Ordenación del Territorio de la Escuela de Arquitectura. Habiéndose expuesto la evolución de la práctica en el periodo analizado como resultado de dicha investigación en otros artículos, se apunta en este caso exclusivamente para situar la relación con el discurso.

\section{DE LA DECLARACIÓN AL PACTO DE ÁMSTERDAM (1975-2016)}

Del análisis del amplio periodo comprendido entre la aparición en 1975 de la Declaración y Carta de Ámsterdam de 1975 a la reciente firma del Pacto de Ámsterdam en 2016, esta investigación distingue tres periodos subdivididos en fases que permiten estructurar la evolución de las políticas analizadas en España: 1) Rehabilitación Integrada y Recuperación de la ciudad de 1975 a 1992; 2) Rehabilitación Urbana y Desarrollo sostenible de 1992 al 2000; y 3) Regeneración Urbana y Desarrollo Sostenible e Integrado de 2000 a 2016. Esta estructuración en periodos y su relación con la evolución de la producción inmobiliaria y con la legislación vinculada a la rehabilitación queda recogida en el siguiente gráfico (figura 1), que guía la exposición.

\footnotetext{
2 Se incluye entre los resultados de la tesis doctoral Matesanz (2017), Políticas urbanas y vulnerabilidad, en la que la Integración en la ciudad se analiza a partir de una serie de parámetros que definen la integración física, ambiental, funcional y política y social que según la autora la componen.

${ }^{3}$ C. Histórico Pamplona/Rochapea, C. Histórico Logroño, C. Histórico Lleida, C. Histórico Santiago de Compostela, C. Histórico Cartagena, Bilbao La Vieja, Barrio del Arrabal (Zaragoza), Trinidad Perchel (Málaga), Lavapiés (Madrid), Río de la Pila (Santander), Poble Sec (Barcelona), La Soledad/Polígono Levante (Palma), Mérida (Mérida), C. del Acero (Avilés-Corvera), La Rondilla (Valladolid), San Cristóbal de los Ángeles (Madrid), Barrios de la Zona Norte (Alicante), Sta. M..$^{a}$ de Benquerencia (Toledo), Sta. M. ${ }^{a}$ del Mar (Sta. Cruz de Tenerife), Polígono Sur (Sevilla).
} 
GAPP. Nueva Época - N. ${ }^{\circ}$ 20, noviembre 2018 - ISSN: 1989-8991 - DOI: 10.24965/gapp.v0i20.10488 - [Págs. 82-99] Número monográfico - Gobernanza y políticas de desarrollo urbano: teoría y práctica

Evolución de los parámetros del enfoque integrado en las políticas de regeneración urbana en los barrios vulnerables en España Ángela Matesanz Parellada / Agustín Hernández Aja

FIGURA 1. ESQUEMA DE LAS ETAPAS Y FASES DELIMITADAS EN RELACIÓN CON LA EVOLUCIÓN DE LA PRODUCCIÓN INMOBILIARIA, LA POBLACIÓN Y LAS PRINCIPALES LEYES, PLANES Y PROGRAMAS VINCULADOS A LA REHABILITACIÓN Y REGENERACIÓN URBANA EN ESPAÑA

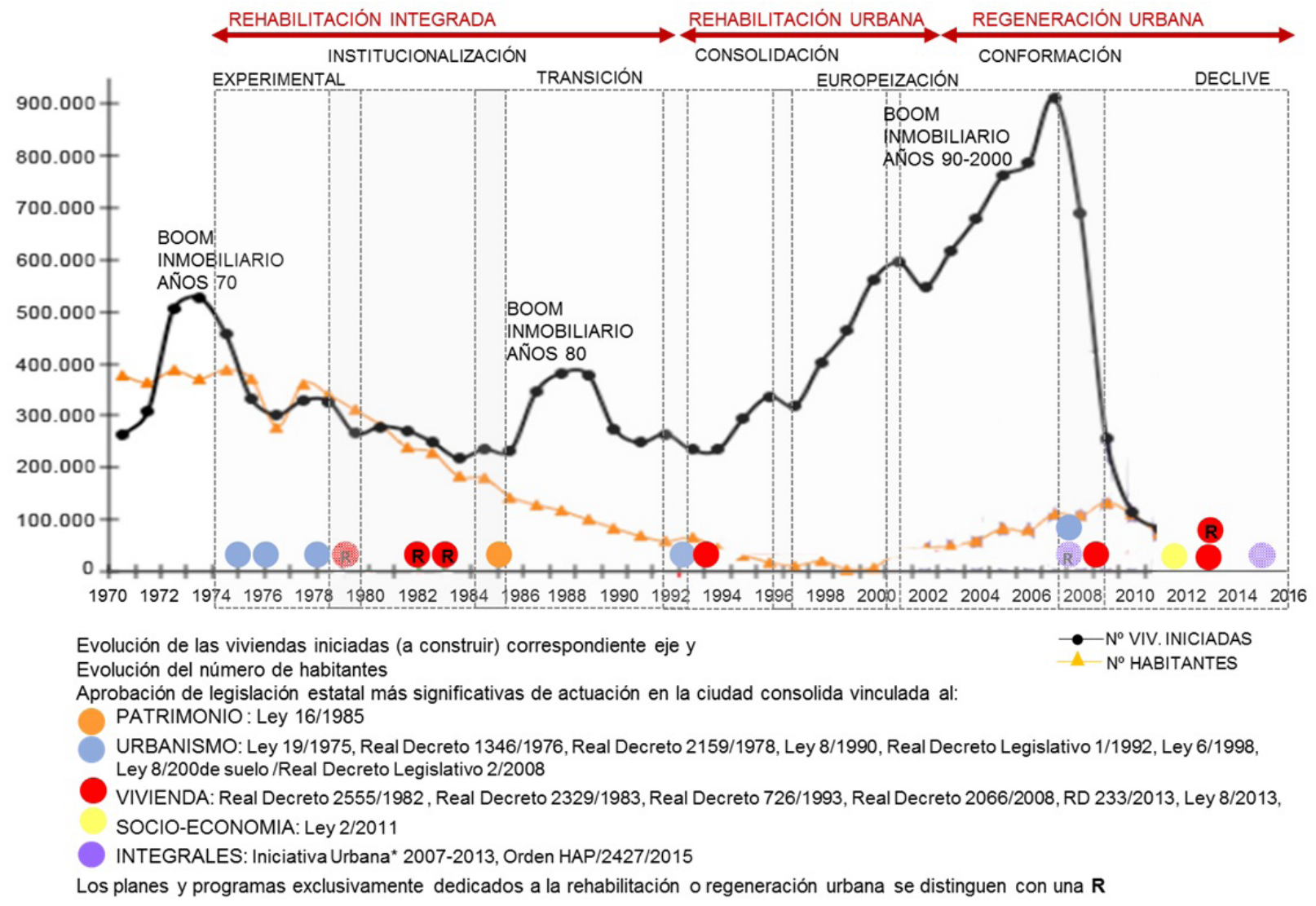

Fuente: Elaboración propia a partir de gráfica de Carpintero (2015). Modificación de Matesanz (2017).

\subsection{La Rehabilitación Integrada y la recuperación de la ciudad (1975-1992)}

\section{Fase Experimental (1975-1979)}

A mediados de los años setenta Europa se encontraba en una situación característica tanto en lo político, económico y social (crisis económica y ecológica, ecos de las grandes movilizaciones políticas y sociales, equilibrio de fuerzas entre los bloques comunista y capitalista, etc.) como en lo urbano (crisis del modelo de desarrollo de grandes periferias y renovación de los centros históricos en declive).

Esto favoreció la aparición, desarrollo y consolidación de una fuerte cultura urbanística en Europa, con base en la sociología marxista francesa, en las prácticas de recupero italianas y en los principios participativos de advocacy planning inglés. Materializada en la recuperación del tejido existente, urbano y social, y en la defensa de un modelo de ciudad en todos sus sentidos -urbanístico, social, económico, ambiental-, se oponía al modelo capitalista desarrollado hasta entonces, considerándolo culpable de los problemas de la ciudad ${ }^{4}$. Resultado de múltiples confluencias (de disciplinas, de investigación y práctica, etc. ), aunque partía del interés por los centros históricos y de la evolución de la protección del patrimonio (otrora aliada de la destrucción de la ciudad existente), se articulaba con la periferia con una visión global y territorial 5 .

En ese contexto económico y político favorable, a pesar de convivir en el discurso internacional con los planteamientos de la «necesaria» y «modernizadora» renovación urbana dirigida a las zonas degradadas

\footnotetext{
${ }^{4}$ Sirvan como ejemplo la descripción de Cervellati, P. L. y Scannavini, R. (1973), de la actuación en Bolonia, convertida en uno de los principales ejemplos a seguir en la época.

5 Distintos autores y múltiples textos de la época como Cervellati, P. L. y Scannavini, R. (1973), Campos Venuti (1978) y de análisis de la misma como Álvarez Mora (1995) o Pol (2006) describen parcialmente estas ideas.
} 
(OCDE, 1978), estas ideas se incorporaron, con menor radicalidad, al marco administrativo internacional. La Carta y la Declaración de Ámsterdam, aprobadas por el Consejo de Europa (CdE) en 1975 en el marco del Año europeo del patrimonio arquitectónico, se convirtieron en un referente al enunciar por primera vez en un documento global «los principios generales y las orientaciones de una política de salvaguarda y de reanimación del patrimonio cultural europeo» $(C d e, 2004: 25)^{6}$. En ellas se defendía la Conservación Integrada como práctica «resultado de la acción conjunta de las técnicas de la restauración e investigación de las funciones apropiadas» que debía ser «llevada a cabo con un espíritu de justicia social», no suponer «el éxodo de todos los habitantes de condición social modesta" y "constituir uno de los pasos previos de las planificaciones urbanas y regionales» (CdE, 1975a: pto.7).

El contexto español de mediados de los setenta estaba marcado por la movilización social y política de la transición y la confluencia de las crisis económica y urbana, visible en la degradación y abandono de los centros históricos y en unas periferias faltas de equipamientos y con problemas desde su construcción.

El discurso legislativo estatal de esta época quedó inicialmente establecido por la reforma la ley del suelo de 1975, gestada en el franquismo y centrada en el desarrollo urbano, que mantuvo los principios de la ley de 1956, articulando la intervención en la ciudad consolidada a través de los planes especiales de protección y reforma interior. Ésta, la reforma interior ${ }^{7}$, enmarcada en el planeamiento general a través de sus planes especiales (PERI), definía un marco amplio en el que entraron tanto la renovación urbana, que había instrumentado los procesos de conservación-destrucción en los cascos históricos (Álvarez Mora, 1995), como la nueva práctica de la rehabilitación.

Sin embargo, con la muerte de Franco, en el contexto de los primeros gobiernos de la UCD, se empezaron a trasladar a la administración parte de las ideas de la Conservación Integrada definida por el Consejo de Europa, coincidentes con las propuestas de las prácticas alternativas vinculadas al movimiento vecinal. Aunque el reglamento de planeamiento de 1978, introdujo algunas nociones vinculadas a la recualificación de los tejidos existentes, las ideas de la Carta y la Declaración de Ámsterdam sólo fueron parcialmente asumidas, en forma de Rehabilitación Integrada, por la puesta en marcha de dos programas experimentales en 1979:

- Los Estudios Básicos de Rehabilitación, de la Dirección General de vivienda, que entendían la Rehabilitación Integrada como un "conjunto de actuaciones coherentes y programadas» que, a través de la mejora del espacio físico en todos sus aspectos, tenían por objetivo la mejora de la calidad de vida de determinadas zonas, atendiendo a los valores «socioeconómicos, ambientales, edificatorios y funcionales» (MOPU, 1981:14).

- Las Operaciones Piloto de Actuación Conjunta, de la Dirección General de Acción Territorial y Urbanismo del Ministerio de Obras Públicas y Urbanismo (MOPU), que partían de la coordinación entre las distintas acciones de la Administración Central y de éstas con las realizadas por la administración municipal. Buscaban la conservación del patrimonio urbano y arquitectónico, la mejora y preservación de la calidad de vida en las ciudades, llevar a la realidad y de forma operativa la vida en esos cascos históricos y alcanzar un «diseño urbano armónico» (MOPU, 1981:12,14).

Aunque destacan por la introducción de estas ideas en el discurso, ambos tuvieron escaso éxito y, a pesar de ser coetáneos a programas piloto lanzados en otros países ${ }^{8}$, no alcanzaron igual desarrollo en la importancia de la participación ciudadana, la territorialidad de las actuaciones y la atención de forma conjunta a las distintas acciones sectoriales.

La práctica de la administración en su conjunto mantuvo, sin embargo, una línea continuista con operaciones de renovación-conservación instrumentadas por los planes parciales y de reforma interior definidos por la ley del suelo ${ }^{9}$. Únicamente, la aparición de contra-planes o planes alternativos, desarrollados por vecinos/as y técnicos -más propositivos que ejecutivos- y articulados en una lucha global por la democracia y el derecho a la ciudad, defendieron enunciados más complejos. Estos se relacionaban con la integración en la

\footnotetext{
6 Traducción propia.

7 Entendida como «Operaciones encaminadas a la descongestión, creación de dotaciones urbanísticas y equipamientos comunitarios, saneamiento de barrios insalubres, resolución de problemas de circulación o de estética y mejora del medio ambiente o de los servicios públicos u otros fines análogos, se relacionan a su vez con parte de estos factores» (RD 2159/1978: Art. 83).

8 Mientras en Reino Unido los Priority Estate Projects aparecieron en 1979, en Francia los Développement Social de Quartiers lo harían en 1982, teniendo ambos según Jacquier (1991) ciertas similitudes, a pesar de sus características y particularidades propias.

9 Como el Plan Parcial Ruavieja de Logroño (1971), el Plan Parcial de Rochapea en Pamplona (1979).
} 
GAPP. Nueva Época - N. ${ }^{\circ}$ 20, noviembre 2018 - ISSN: 1989-8991 - DOI: 10.24965/gapp.v0i20.10488 - [Págs. 82-99]

Número monográfico - Gobernanza y políticas de desarrollo urbano: teoría y práctica

Evolución de los parámetros del enfoque integrado en las políticas de regeneración urbana en los barrios vulnerables en España Ángela Matesanz Parellada / Agustín Hernández Aja

ciudad, de los agentes y la consideración a cuestiones que abarcaban desde la mejora física de los barrios, urbanística y de vivienda, a otras de carácter político y social ${ }^{10}$.

\section{Fase de consolidación de la Rehabilitación Integrada (1980-1985)}

A principios de los ochenta la entrada de las políticas neoliberales al gobierno de Reino Unido, la prolongación de la crisis y los cambios estructurales que introdujo la salida de ésta favorecieron la consolidación de la idea de la falta de recursos de la administración ${ }^{11}$ que darían pie al cuestionamiento del Estado del Bienestar por parte de distintas organizaciones internacionales.

A pesar de ello, algunas mantuvieron las ideas de la etapa anterior su discurso. La ya Rehabilitación Integrada consideraba la intervención tanto en los centros urbanos como en las periferias -atendiendo a diferentes escalas y problemáticas-, entendía que la capacidad de decisión era de los ciudadanos y apuntaba como problemas emergentes de la época los ambientales y el creciente desempleo (CdE, 1982). La inicial relación con el patrimonio, sin embargo, empezó a debilitarse, lo que se confirmó con la vuelta a posiciones conservacionistas de las convenciones sobre patrimonio ${ }^{12}$.

En España, con la llegada de los ayuntamientos democráticos se inició la institucionalización de la rehabilitación; tanto desde la práctica, por la asunción de los planes alternativos y el desarrollo de planes generales de ordenación urbana (PGOU), que asumían en modelo de ciudad defendido por la Conservación Integrada ${ }^{13}$, como desde la legislación.

La aparición de legislación relativa a la rehabilitación urbana, representada por el Real Decreto 2329/1983, introdujo en los textos legislativos la Rehabilitación integrada. A pesar de tener una visión que superaba la exclusiva conservación del patrimonio e incorporaba las relaciones con los aspectos físicos, sociales o económicos ${ }^{14}$, se configuró desde un punto de vista sectorial, ligado en último término a la rehabilitación de la edificación y vinculado a los planes de vivienda. Además, elaborada en un momento de crisis económica, incluía como objetivos tanto la salida de la misma, como la creación de empleo en el sector de la construcción, conservando los objetivos de los planes de vivienda previos que tenían como eje el desarrollo económico ${ }^{15}$.

Las intervenciones propuestas en ese momento de efervescencia avanzaron y mejoraron en sus planteamientos de integración en la ciudad gracias a su incorporación en los nuevos planes generales, que establecieron el modelo de ciudad desde la recuperación de los barrios (no sólo a través de PERI, sino de Planes de Mejora, nuevas ordenanzas y re-equipamiento). Sin embargo, los múltiples problemas que rodearon a la creación y organización de las administraciones y nuevas formas de hacer en ese periodo llevaron a una ralentización de los procesos y de su puesta en marcha. Esto conllevó el agravamiento de la situación física (en los centros) y social (en la periferia) y al aumento de la distancia entre el discurso y el desarrollo legislativo desde la administración central y las necesidades surgidas de la práctica ${ }^{16}$.

\section{Fase de transición de modelo (1985-1991)}

A mediados de los ochenta, mientras Europa salía del periodo de crisis a través de la implantación progresiva de las ideas liberales llegadas de EEUU y Reino Unido, la consolidación de la Comunidad Económica Europea (CEE) con la firma del Acta única europea, hizo que el discurso economicista sobre temas urbanos de esta institución tomara cada vez un mayor peso.

10 Como el representado por los vecinos y vecinas de los barrios Trinidad y Perchel en Málaga, que se opusieron a la ordenanza municipal de 1971 que podía suponer su transformación y la expulsión de las personas residentes.

11 Esta cuestión se menciona tanto en documentos de las OCDE (1978), como de la ONU (1980).

12 Como muestra el análisis de la Convención para la salvaguardia del patrimonio arquitectónico de Europa (Cde, 1985).

13 Ejemplo de ello es la aprobación en la década de los ochenta de numerosos PGOU como los de Málaga y Alicante (1983); Valladolid y Pamplona (1984); Madrid y Logroño (1985); Toledo, Avilés y Zaragoza (1986), Mérida, Cartagena y Santander (1987), y Sevilla (1988).

14 «(...) la mejora o recuperación de conjuntos urbanos o áreas rurales, de sus condiciones naturales, de las actividades económicas y sociales y de las condiciones de vida de sus residentes» (RD2329/1983 pto 3 Art 1).

15 «El fomento general de la actividad rehabilitadora y de la creación de empleo en el sector de la construcción son objetivos que se contemplan con los de la creación de regímenes protegidos de rehabilitación» (...) (RD2329/1983: Prólogo).

16 Estas además de mostrarse en los casos de referencia aparecen parcialmente reflejadas en distintos textos como Rubio del Val (1990) y Pol (2006). 
En paralelo, en un marco de creciente desigualdad y exclusión en el que las ciudades de algunos de sus principales miembros, como Francia y Reino Unido, visibilizaban conflictos sociales, la CEE empezó a apuntar a la necesaria definición de un nuevo Modelo Social Europeo a través de la integración territorial. Este se materializó en la incorporación y desarrollo de investigaciones y programas comunitarios dirigidos a frenar el declive social y económico tanto en el centro de las ciudades como en los barrios de la periferia (UE,1998b). Más allá de los planteamientos experimentales que desde lo social se desarrollaron en el marco del Poverty I, los Proyectos Pilotos Urbanos, planteaban ya al final de este periodo "programas de enfoque integrado», "estrategias de mejora del medio ambiente», "estímulo del nuevas actividades económicas y recuperación de los edificios antiguos» $y$ "al desarrollo de vínculos entre la investigación y el desarrollo de actividades a nivel local, PYME, universidad y otros interesados» (UE,1998b:4 ${ }^{17}$ ).

El discurso de actuación integrada sobre barrios desfavorecidos no fue sin embargo adoptado aún en España, que además de tener una tradición diferente de actuación, tenía problemas de distintas características. A pesar de ello, sí que empezó a visibilizarse un cambio en el modelo de ciudad mayoritariamente propuesto. El paso a un modelo económico en el que volvía a incentivarse la construcción, apoyado en cambios legislativos y favorecido por las ayudas europeas y las inversiones extranjeras, se articuló con el abandono de la visión global y el planeamiento. Las prácticas que desde las instituciones desarrollaban las rehabilitaciones previstas, pasaron a un segundo plano, a la vez que se consolidaba su carácter sectorial ligado a la edificación en la que se concentraban las ayudas ${ }^{18}$.

Aunque el desarrollo de los planes generales y de los PERI, fundamentalmente de las zonas centrales, se mantuvo, este cambio de modelo coincidió con una materialización de estos, fundamentalmente basada en las cuestiones físicas. Triunfó con ello según Terán (1984:68), la "autonomía metodológica de la arquitectura», al dejar en un segundo plano otros aspectos como los territoriales, urbanísticos o ambientales y reducir las cuestiones sociales y económicas al esfuerzo por el mantenimiento de la población y su realojo. A pesar de que los planteamientos de esta época, sí que mantuvieron la necesidad de emplear instrumentos que integraran y atendieran conjuntamente a todas estas cuestiones, especialmente a las urbanísticas y sociales, la idea de que la mejora física traería mejora social (Bohigas, 1986), y el interés del análisis morfológico y la calidad espacial, se fueron consolidando.

Estas acciones no fueron suficientes para luchar contra los problemas que se agolpaban en los centros históricos, degradación física de las viviendas (Rubio del Val,2011), ni en las periferias, que tenían otro tipo de problemas sociales y económicos. Estos generalmente se trataron de forma sectorial y marginal, a pesar de las iniciativas puestas en marcha desde el área social, como la red de atención de Servicios Sociales Municipales impulsada en 1988 por el Plan Concertado de Prestaciones Básicas de Servicios Sociales de Corporaciones Locales.

\subsection{Rehabilitación Urbana y el Desarrollo Sostenible (1992-2000)}

\section{Fase de consolidación de la Rehabilitación Urbana (1992-1996)}

En los años noventa, la consolidación del modelo económico, reforzada por el Tratado de Maastricht y favorecida por la caída del comunismo, afianzó en el discurso la ideología neoliberal y de la imposibilidad de mantenimiento del Estado de Bienestar ${ }^{19}$. La competitividad económica pasó a ser uno de los principales objetivos de las ciudades que señalaban como principal freno para conseguirla el aumento de los problemas medioambientales y la exclusión social producidos por las fuertes transformaciones urbanas vinculadas a la aceleración de la actividad económica y de la internacionalización impulsadas por el mercado único (CEE, 1990:8).

La preocupación por el medio ambiente, manifestada por distintos organismos internacionales desde los años setenta, fue ampliándose y consolidándose en el marco internacional en paralelo a la mayor visibilidad de los problemas generados por la contaminación. La aparición del Libro Verde del Medio Ambiente Urbano de la CEE (1990) y la Declaración de Río de la ONU (1992), consolidaron la introducción del principal vector de cambio de este periodo, el Desarrollo Sostenible. Éste, rápidamente fue absorbido por el discurso de la

\footnotetext{
17 Traducción propia.

18 Entre los casos analizados se observa como en esta época se consiguieron poner en marcha las acciones de rehabilitación de vivienda en los cascos históricos de Pamplona, Logroño y Lleida y en los barrios Malagueños de Trinidad y Perchel.

19 Como muestra, por ejemplo, la lectura de OCDE (1994).
} 
ciudad competitiva, al considerar que a través de sus tres pilares (cohesión social, medio ambiente y desarrollo económico) conseguiría la armonía imposible entre el mercado y los problemas generados por él ${ }^{20}$.

La Regeneración Urbana encontró fácil encaje en el Desarrollo sostenible como una acción dirigida a zonas que concentraban bolsas de pobreza, criminalidad y drogadicción, con problemas económicos, sociales y ambientales (CEE, 1990:4). Así, la línea heredera de la renovación urbana que venía siendo defendida y trabajada por instituciones como la CEE y la OCDE, influida por la desarrollada por países como Reino Unido, se consolidó como tendencia en el marco internacional ante el aumento de la exclusión y la tensión social vinculado a la extensión de la globalización y del viraje neoliberal de las políticas urbanas.

En España, sin embargo, aunque las ideas de la ciudad competitiva y los planteamientos estratégicos para situar a las ciudades en el marco internacional encajaron bien en el momento en el que los grandes eventos habían desembarcado en muchas de ellas ${ }^{21}$, las acciones en barrios considerados desfavorecidos, que no se identificaban, en el caso español, como una amenaza para la cohesión social ni para la inversión, no se generalizaron en la práctica, aunque sí aparecieron en el discurso.

Por un lado, la reforma de la ley del suelo que culminaría en el texto refundido de 1992, aunque apenas introdujo variaciones en relación a la reforma interior, sí incorporó la denominación de "operaciones integrales de reforma interior» (RD1/1992:Art.85) y facilitó, a través del aprovechamiento tipo, las intervenciones en la ciudad consolidada (Molina, 2007). Por otro lado, como apunta María Castrillo (2013), el Plan 1992-1995, que caracteriza el discurso en esta etapa y que estableció las bases de los programas de rehabilitación en áreas hasta 2013 (Hernández et alt., 2014), incorporó la explícita «recuperación de zonas o barrios en proceso de degradación, mediante actuaciones de carácter integral» (RD 726/1993). En ella, a pesar de la vinculación al planeamiento y a la mención a algunas consideraciones sociales y económicas en la memoriaprograma, las acciones financiadas se limitaban a la edificación y ocasionalmente a la urbanización. Mientras, la integración de los agentes, quedaba establecida simplemente por los convenios de colaboración entre las administraciones, por la formación de comisiones de seguimiento y por el establecimiento de oficinas de apoyo a su desarrollo en las áreas.

La Rehabilitación Urbana se consolidó con una visión sectorial de la mano de las ayudas para su desarrollo en los planes de vivienda (con el RD 2190/1995). Sin embargo, al pasar a ser un elemento marginal para el sector inmobiliario, la conservación o no de los principios que había defendido la Rehabilitación Integrada y/o la búsqueda de planteamientos más complejos, quedaba en manos de las acciones defendidas en el ámbito local que dependían de los vecinos y vecinas, los técnicos y los políticos implicados en ellas y que precisaban otras financiaciones. En ese marco, no se produjo un cambio sustancial en el desarrollo mayoritario de la práctica de la Rehabilitación Urbana, a pesar de coincidir con un paulatino incremento de acciones en la periferia que generalmente había quedado fuera de las grandes trasformaciones de las ciudades y manifestaba importantes problemas ${ }^{22}$.

\section{Fase inicial de la europeización y entrada del Desarrollo Sostenible (1996-2000)}

A mediados de los noventa, la hegemonía del Desarrollo sostenible y de la corriente vinculada a la actuación en barrios desfavorecidos era un hecho en el discurso internacional, tanto en documentos de carácter social [Carta Social Europea (Cde,1996)], como territorial [Hacia una política Urbana Europea (UE,1997) - Estrategia Territorial Europea (UE,1998a)], en los que ya estaba normalizada y extendida la terminología empresarial y la visión de ciudad como motor económico ${ }^{23}$.

La proliferación de los textos, intercambios y redes europeos y el aumento del número de proyectos integrales financiados por la UE en España empezó a llevar a considerar este tipo de intervenciones en barrios «degradados» en el país (De Gregorio, 2012), especialmente en el contexto teórico o académico ${ }^{24}$.

Estas ideas no tuvieron, sin embargo, presencia alguna en el discurso legislativo del planeamiento de la época, que seguía centrado en favorecer el papel del desarrollo urbano como motor económico. El discurso

\footnotetext{
20 En los textos internacionales encontramos algunas menciones a estas cuestiones como por ejemplo en UE (1996:14).

21 Como por ejemplo en la Barcelona de las Olimpiadas, en la Sevilla de la Expo o en el desarrollo del Plan Bilbao Ría 2000.

22 Aunque las principales acciones y financiaciones recayeron en zonas centrales, se consolidó la intervención en zonas periféricas como San Cristóbal de los Ángeles (Madrid) o el Polígono Sur (Sevilla).

23 Por ejemplo, apunta como objetivos «mantener las ciudades europeas al frente de una economía globalizada y competitiva» (UE,1997:9) o «Acrecentar la prosperidad económica y el empleo en las pequeñas y grandes ciudades» (UE,1998: 2).

${ }_{24}$ Por ejemplo, la participación de España en el programa de la OCDE de delimitación de Barrios Desfavorecidos no llegó a tener una repercusión directa sobre los planes y programas desarrollados por el Ministerio de Vivienda responsable del trabajo.
} 
de la Ley de Régimen del Suelo y valoraciones 6/1998, centrado en defender una mayor liberalización, sí que incorporó tangencialmente una mayor flexibilidad en la transformación del suelo urbano existente, aunque sin considerar su «integralidad».

Por su parte, la Rehabilitación Urbana, como práctica minoritaria y sectorial, se mantuvo en el discurso del Plan de vivienda 1998- 2001(RD 1186/1998) sin grandes variaciones, asumiendo los planteamientos y el grado de integración de los parámetros el enfoque integrado de la etapa anterior.

En la práctica, que desde mediados de los ochenta se había ido consolidando en intervenciones sectoriales menos coordinadas con los agentes y cada vez más desligadas de la visión de ciudad, se fueron incorporando parte de las ideas del enfoque integral europeo (Matesanz y Hernández, 2014). Por un lado, habiéndose demostrado la insuficiencia de las acciones sectoriales, a algunos procesos de rehabilitación se fueron sumando -generalmente sin coordinación- programas de carácter social y/o económico ${ }^{25}$. Por otro lado, se desarrollaron en esta fase los proyectos de las dos convocatorias del programa Urban I, aunque a pesar de introducir la consideración de los agentes y de distintas cuestiones (medioambientales, sociales, o económicas), no presentaron un enfoque integrado efectivo (De Gregorio, 2014:263).

\subsection{La Regeneración Urbana (2000- 2016)}

\section{Fase de configuración de un nuevo tipo de intervención (2000-2006)}

El inicio de los años dos mil quedó marcado en el contexto internacional, por un lado, por la aprobación de la Estrategia de Lisboa y por otro por los atentados de Nueva York.

Siguiendo la tendencia de la fase anterior, los documentos internaciones se multiplicaron. Tanto los relativos al desarrollo sostenible y a temas urbanos, como el Programa de Acción de Lille (2000), Urban Acquis (2004), Acuerdo de Bristol (2005), Estrategia Temática de Medio Ambiente Urbano (2005) o Estrategia Revisada Desarrollo Sostenible (2006) de la Unión Europea. Como los dedicados a la cohesión social y a temas sociales y económicos, como la Agenda Social Europea (UE, 2000) y Estrategia de Cohesión social (CdE, 2004). En ellos se reforzaron la importancia y la necesidad de la competitividad en el territorio y en las ciudades ${ }^{26}$ y el discurso del miedo vinculado a la creciente segregación y tensión social ${ }^{27}$.

En el caso español, el discurso de la administración central se caracterizó por su dualidad. Por un lado, en su desarrollo de nuevas estrategias (como las de Medio Ambiente, EMAU, y Desarrollo Sostenible, EEDS), planes (como los Planes Nacionales de Acción por la Inclusión Social PNAIS) vinculados a la UE, introdujo su discurso hegemónico. Este promovía el Desarrollo Sostenible y con él tanto importantes avances en las cuestiones medio ambientales, como la competitividad en los territorios y la actuación, multisectorial y participada, en barrios vulnerables ${ }^{28}$. Por otro lado, mantuvo el discurso de la rehabilitación urbana en los sucesivos planes de vivienda (Plan 2002-2005 y Plan Estatal 2005-2008); su relación con el planeamiento, la mención a la atención a cuestiones sociales y económicas para la concesión de ayudas que financiaban acciones de mejora física y la coordinación reducida a la firma de los convenios para las ayudas y su comisión de seguimiento. A pesar de ello, sí que los planes de vivienda introdujeron en el discurso en el periodo comprendido entre 2001 y 2006 la coordinación con los PNAIS y la preocupación por el difícil acceso a la vivienda ${ }^{29}$.

\footnotetext{
25 Por ejemplo, los procesos de rehabilitación de los centros históricos de Pamplona y Lleida, de Trinidad y Perchel (Málaga) o el Polígono Sur (Sevilla), incorporaron en este periodo planes y/o acciones de tipo social o medio ambiental.

26 Tómense como ejemplos: «La Agenda ha de reforzar el papel de la política social como factor de competitividad» (UE, 2000:1); "Impacto de alta calidad, ponderando de manera equilibrada la dimensión social, medioambiental y económica del desarrollo sostenible (considerando su dimensión exterior y los costes de la inacción)» (UE, 2006:11); "The role of cities and urban regions as driving forces for regional, national and European development, especially in achieving the goals of the Lisbon and the Gothenburg agendas» (UE, 2004:1.6).

27 Véase como ejemplo: "The search for greater social cohesion means that remedies must be found to the gross situation of possible tensions» (UE, 2000:98), «(...) un número cada vez mayor de zonas urbanas muestra síntomas de tensión» (UE, 2004:4).

28 Encontramos ejemplos tanto en los PNAIS, como «Favorecer planes integrales y comunitarios para barrios degradados y zonas de transformación social (...)» (MTAS, 2001:17) o "La marginación, como temática de acción pública, requiere abordajes integrales en su definición y horizontales o transversales en sus procesos de gestión» (MTAS, 2001:5), como en la EEMAU con «Recuperar las zonas vulnerables y barrios en crisis social y ambiental, fomentando la integración social y la mezcla de usos y rentas en todas las zonas urbanas» (EEMAU, 2006:15).

29 «Contribuir al logro de los objetivos de una serie de políticas estatales de carácter social: la política de cohesión social, facilitando el acceso a viviendas dignas, en alquiler o en propiedad, a los grupos de población con ingresos reducidos, en sintonía con el Plan Nacional de Acción para la Inclusión Social (...)» (RD1/2002: Prólogo).
} 
En ese contexto, aunque la práctica oficial de la Rehabilitación Urbana vinculada a los planes de vivienda, a rasgos generales, se seguía desarrollando según lo establecido en las etapas anteriores, los problemas de las zonas centrales y, especialmente, de la periferia y la influencia de los programas europeos que se venían desarrollando llevaron a la proliferación en la práctica real de nuevos planes y acciones complementarias que buscaban atender a los problemas no tratados desde el marco general fijado para la rehabilitación ${ }^{30}$. En paralelo a estos y a los programas de rehabilitación tradicionales, aparecieron programas autonómicos de carácter integral, como Izartu o el Pla de Barris, que se sumaban a los Urban II financiados por Europa, y planes creados adhoc en determinados barrios que se percibían como un problema (Polígono Sur de Sevilla o Barrios del norte de Alicante). Estos, aunque surgieron con presupuesto y personal propio, establecían la articulación del plan y las propuestas con parte de las financiaciones y planes existentes (ARI, Urban, etc.).

En 2007, cuando se consolidó dicha dualidad con la mención en la Ley 8/2007 del suelo al desarrollo sostenible (L8/2007:Art2) y el interés por la ciudad existente (L8/2007: prólogo) y por la regeneración urbana apoyada en acciones integrales en barrios promovidas por el estado con financiación europea por la Iniciativa Urbana 2007-2013, los cambios económicos marcaron el inicio de un cambio de fase.

\section{Fase de declive y nueva transición (2007- 2016)}

La llegada de la crisis económica a un marco europeo, que ya se caracterizaba por el aumento de la desigualdad, empezó a situar a los barrios vulnerables y a la regeneración urbana como posible respuesta en el centro del discurso con la Carta de Leipzig, la Declaración de Marsella, la Declaración de Toledo y finalmente las Estrategias de Desarrollo Urbano Sostenible (EDUSI). Esto se producía, sin embargo, de forma simultánea al mantenimiento y consolidación en la década siguiente de las ideas que planteaban la falta de fondos públicos y favorecieron la sustitución de los programas Urban por una herramienta financiera, JESSICA (Joint European Support for Sustainable Investment in City Areas) ${ }^{31}$.

En el caso español, en el que la crisis supuso el parón inmobiliario y la visibilización graves problemas sociales y económicos, desde el estado se empezó a recuperar importancia la rehabilitación urbana, entendida como un posible motor económico alternativo al de la construcción. Se introdujeron en esta línea algunos cambios visibles en el plan de vivienda de 2008 (RD2066/2008); a) la financiación de la renovación urbana (práctica generalmente más lucrativa para los promotores que la rehabilitación) (introducida en el RD14/2008), b) un especial énfasis en la mejora del acceso a la vivienda y c) una mayor atención a la rehabilitación. Ésta, más allá de su introducción en el nombre del plan (de Vivienda y Rehabilitación), se tradujo en el mayor desarrollo de esta práctica junto a la que se introducía una nueva modalidad dirigida a la mejora de la eficiencia energética y de la accesibilidad.

Esta línea de interés por la rehabilitación se consolidó con la aparición de la Ley de economía sostenible en 2011 y con la Ley 8/2013 de rehabilitación, regeneración y renovación urbanas y el Plan Estatal de fomento del alquiler de viviendas, la rehabilitación edificatoria, y la regeneración y renovación urbanas, 2013-2016 vinculado a ella, en 2013. Con ellas, y con la aparición en 2015 de la Orden HAP/2427/2015 que lanzó la primera convocatoria de EDUSI, se establecería una triple práctica; 1) la tradicional de mejora de la edificación 2) la de las intervenciones vinculadas a la accesibilidad y principalmente al ahorro energético, que se esperaba fuera ese motor económico, sustituto de la construcción y 3) las intervenciones de Regeneración Urbana en Barrios Vulnerables, difícilmente sería financiable sin las ayudas públicas (Matesanz y Castrillo, 2015).

Mientras las dos primeras se plantean desde un punto de vista sectorial (en la edificación y), las últimas se presentan como integradas, multisectoriales y participativas.

Desde la práctica, aunque este periodo se caracterizó desde su inicio por la concesión de las numerosas ayudas de las Iniciativas Urbanas 2007-2013 y del Plan de Vivienda y Rehabilitación 2009-2012, estas tuvieron, en algunos casos, dificultades para ponerse en marcha, y las que ya lo estaban, empezaron a ralentizarse o tener problemas de financiación, reactivándose sólo en los últimos años algunos planes.

30 Tanto de participación (como el Diagnóstico del Plan Comunitario del Casco de Pamplona, en 2004 y 2006 , el Proyecto de Desarrollo comunitario y dinamización social de Trinidad Perchel en 2004), de accesibilidad (como el Proyecto de Movilidad y accesibilidad de Río de la Pila de 2007), como de fomento del comercio o del empleo (como el Plan de Revitalización de Lavapiés).

31 Iniciativa de la Comisión Europea, en colaboración con el Banco Europeo de Inversiones (BEI) y el Banco de Desarrollo del Consejo de Europa (BDCE), que busca «fomentar la regeneración y el desarrollo urbano sostenible por medio de mecanismos de ingeniería financiera» (UE, 2007). 


\section{CONCLUSIONES: LA EVOLUCIÓN DE LOS PARÁMETROS DEL ENFOQUE INTEGRADO}

El análisis de los textos internacionales lleva a plantear la existencia de dos corrientes o tendencias en el marco de las políticas de regeneración urbana, caracterizadas por una diferente evolución en los parámetros del enfoque integrado:

- La que llamaremos (Conservación) Rehabilitación Integrada: surgida en los años sesenta y setenta, con base en la sociología marxista y el recupero italiano, se caracterizó por el respeto al tejido urbano y social existente y defendió inicialmente desde el discurso: 1) la integración de las áreas temáticas y disciplinas buscando atender a las necesidades y problemas de la ciudad (sociales, económicos, físicos, ambientales) atribuidos al modelo capitalista, 2) la integración y colaboración de todos los agentes surgida en torno a las necesidades, que apuntaban al necesario diálogo entre ciudadanos y técnicos de distintas disciplinas, al apoyo de la opinión pública, a la importancia de la información y a la participación activa de los ciudadanos/as en la toma de decisiones, al papel de control sector público sobre los intereses de mercado y la oposición a la especulación, y 3) la necesaria integración de los barrios o áreas a rehabilitar en el conjunto de la ciudad. A pesar de su fuerza inicial los problemas en su materialización y los cambios políticos y económicos llevaron a una pérdida paulatina de presencia e influencia en el marco internacional, paralela a la absorción de la ideología.

- La que llamaremos Regeneración Urbana, surgida a finales de los años setenta, extendida a partir de los noventa y con base en las políticas liberales y neoliberales que con el paso de los años se fueron consolidando en Europa. Caracterizada en el discurso por sus objetivos económicos y por la falta de definición material, en este ha destacado por: 1)el mantenimiento a lo largo de los años de la importancia de la integración de las áreas y su evolución hacia un mayor aprovechamiento de sus sinergias, 2) una integración de los agentes con una participación controlada y de consenso y 3)con una visión inicial reducida al barrio que con el paso del tiempo se ha ampliado a su relación con el resto de la ciudad, aunque con una visión reducida al apertura.

Podemos considerar que ambas han influido y condicionado la evolución de los parámetros del enfoque integrado en las políticas estatales y en su aterrizaje en la práctica real, mucho más condicionada sin embargo por los condicionantes locales.

\subsection{Integración de las áreas}

A pesar de la influencia internacional, en España la integración de las áreas ha tenido una menor presencia en el discurso de actuación sobre la ciudad consolidada y su evolución y desarrollo en las distintas fases han sido distintos:

- Fase Rehabilitación Integrada (1975-1992): Tal y como planteaba en el marco internacional la Rehabilitación integrada, se puede considerar que el discurso de los programas experimentales de 1979 muestra un cierto esfuerzo por considerar lo poliédrico de la problemática de los barrios. A pesar de ello, el desarrollo de estos programas terminó siendo sectorial, vinculado a las acciones físicas, a la edificación principalmente. Esta sectorialidad se mantuvo en el discurso y la práctica en la institucionalización de la Rehabilitación Integrada como práctica en España a través de la política de vivienda (cuyo objetivo primero era el apoyo a la economía y la generación de empleo).

Aunque la legislación del suelo de la época (TDR 1976) mantuvo la continuidad con los planteamientos de la de 1956, se puede considerar que el acercamiento a través del planeamiento urbano, que definía en último término los planes de actuación en los barrios a través de PERI y de acciones de mejora urbana, sí que aportaba una visión más compleja. Esta no planteaba, sin embargo, acciones de otro tipo, ni su articulación con planes sociales o económicos. Así, aunque en los planes alternativos y en el propio discurso teórico (no administrativo) se contemplaban distintas cuestiones, en la práctica real, bien por la urgencia de lo físico, bien por la creencia de que la mejora física traería aparejada una mejora social, no se articularon otras medidas.

- Fase Rehabilitación urbana y desarrollo sostenible (1992-2000): A pesar del mantenimiento de la rehabilitación urbana como una práctica sectorial, el enfoque integrado sí apareció en el discurso administrativo estatal de los noventa. A través de nuevas prácticas de Regeneración Urbana lle- 
gadas de Europa, se decía buscar fomentar el desarrollo económico y la cohesión social, tomaban como esencial su condición de integrales y/o multisectoriales.

- Fase Regeneración Urbana (2000-actualidad): Aunque con cierto retraso respecto al marco internacional del que procedía, en los años dos mil estas ideas aparecieron en los programas autonómicos de actuación en barrios, en la Iniciativa Urbana 2007- 2013 y en documentos con visión más global como la EEMAU. Más allá de su presencia posterior en los textos administrativos, la continuidad y aparición de problemas de distinta naturaleza y difícil solución en los barrios, llevó a la demanda de acciones complejas y articuladas desde la práctica, contribuyendo a la extensión de estas ideas.

A pesar de la irrupción en el discurso de la integralidad de las áreas y su consolidación en las acciones en barrios vulnerables, con la llegada de la crisis económica y el entendimiento de la rehabilitación como posible motor económico, ha ganado peso de nuevo la visión sectorial, también física, pero en este caso ligada a la rehabilitación energética y de la accesibilidad, manteniendo relegada la multisectorialidad a la actuación en barrios vulnerables.

Podemos considerar, por tanto, que, tras el inicial fracaso de la integración de las áreas en la institucionalización y las primeras prácticas de la Rehabilitación Integrada y la Rehabilitación Urbana, fue la Regeneración Urbana la que hizo de dicha integración una seña de identidad en el discurso. Aunque esta la mantienen las EDUSI, en los últimos tiempos gana fuerza la visión sectorial que se da de la Rehabilitación Energética.

\subsection{Integración de los agentes}

Los dos enfoques presentes en el marco internacional y su diferente naturaleza al tratar la integración de los agentes han tenido su correspondencia en el discurso estatal:

- Fase Rehabilitación Integrada (1975-1992): Las prácticas alternativas de mediados y finales de los setenta, que partían de la iniciativa ciudadana, se caracterizaron por una fuerte integración de los agentes, coincidente con los planteamientos de la Rehabilitación Integrada del marco internacional. Sin embargo, esas ideas quedaron lejos del discurso administrativo estatal y su materialización, apuntando únicamente cierta integración en los programas experimentales de 1979, pero sin llegar a consolidarse a nivel administrativo en la institucionalización de la rehabilitación en el marco de la vivienda. Aunque hacía referencia al respeto al tejido social y a la permanencia de los habitantes, no desarrolló ni su coordinación, ni su participación. Ésta sólo aparecía en la legislación urbanística a través del mantenimiento de los periodos de información y alegaciones estipulados.

- Fase Rehabilitación urbana y desarrollo sostenible (1992-2000): Reducida la participación a la reglada por el planeamiento y la coordinación a la establecida por los convenios entre administraciones de los programas ARI, la integración de los agentes a penas se consideró en un amplio periodo, en el que la movilización ciudadana fue menor. Mientras, la participación de los agentes implicados promovida por las administraciones y la idea de la de la necesaria financiación privada ante la falta de fondos públicos, que abrieron la puerta al emprendimiento ciudadano y los partenariados, pasaron a ser una pieza esencial de la Regeneración Urbana en un contexto europeo caracterizado por el acercamiento a las políticas neoliberales.

- Fase Regeneración Urbana (2000-actualidad): A pesar del aterrizaje en España del planeamiento estratégico y, principalmente de los primeros PPU y Urban, y de la aparición de nuevas propuestas desde la administración para incorporar la participación y voluntades de los vecinos en los años noventa, estas ideas no se incorporarían como tales al discurso administrativo hasta la aparición en los dos mil de textos no normativos, como el Libro Verde del Medio Ambiente Urbano, y de su desarrollo práctico estatal, mediante la Iniciativa Urbana 2007-2013.

En el conjunto del periodo analizado, se pude considerar que si bien la integración de los agentes que se produjo en un origen desde las prácticas impulsadas por el movimiento ciudadano, no tuvo igual reflejo, continuidad ni apoyo en el discurso administrativo de la Rehabilitación Integrada, (a pesar de su mención inicial en los programas experimentales y en los buenos propósitos del RD 1983), ni en la Rehabilitación Urbana de los años noventa, esta se recuperó de forma muy diferente con la coordinación y la participación reglada promulgada por la Regeneración urbana. 


\subsection{Integración en la ciudad}

La integración en la ciudad ha sido la menos explicitada tanto en el marco internacional como en el estatal, en el que ha tenido, a través del planeamiento urbano, un peso especial por tratarse de una de las herramientas de articulación de las intervenciones en la ciudad consolidada. Se distinguen en este caso:

- Fase Rehabilitación Integrada (1975-1992): La importancia de la ciudad en su conjunto, la relación entre el centro y la periferia y la demanda de justicia social incluidas en el discurso de la Conservación Integrada, que llevan a considerar su alto grado de integración, resultaron clave en los planteamientos de los primeros planes alternativos y los programas experimentales. Sin embargo, estas ideas no llegaron de igual manera a la legislación estatal: no se estableció un sólido marco de actuación global que permitiera la recuperación de los barrios y la ciudad al centrarse en los nuevos desarrollos. Esta Integración pasó a depender exclusivamente del buen hacer del planeamiento, que a pesar de presentarse con primeros PGOU de la democracia como una buena herramienta de integración, resultó con el tiempo insuficiente.

- Fase de Rehabilitación urbana y desarrollo sostenible (1992-2000): La pérdida paulatina de la visión holística en España, coincidente tanto con el triunfo de la arquitectura y el proyecto, como con la irregular salida de la crisis y la entrada en el incipiente capitalismo global a mediados de los ochenta, llevó a un cambio en las intervenciones propuestas en la ciudad. Del modelo recuperador de la ciudad de la Rehabilitación Integrada, se pasó a uno extensivo, en el que la rehabilitación era un hecho puntual y secundario.

La pérdida de la visión de conjunto de la ciudad y el simultáneo agravamiento de la segregación urbana, que enlazaron fácilmente con las propuestas de actuación delimitada en barrios vulnerables, sólo se vieron contrarrestadas por la recuperación de la integración, a través de la movilidad y el transporte y de la preocupación por cuestiones medioambientales potenciadas por la UE. Sin embargo, éstas apenas tuvieron peso en un discurso ligado a la vivienda, aunque sí se consideraron en mayor medida en la práctica real.

- Fase Regeneración Urbana (2000-actualidad): Demostrada la insuficiencia de estas acciones, en los años dos mil se empezó a recuperar en el marco europeo la necesidad de estrategias de carácter global que llegaron de la mano de operaciones de apertura de algunos barrios entendidos como guetos y posibles amenazas, en las que se buscaban sólo su integración física y su conexión con la ciudad. Se puede considerar que la aparición de las EDUSI (Orden HAP/2427/2015), sí que ha incorporado una visión más global, aunque apenas se han desarrollado o trascendido aún en España en un contexto en el que se sigue debatiendo sobre la necesidad o no de planeamiento y de los problemas de sus instrumentos.

A rasgos generales, la integración en la ciudad, que se presentaba como una seña de identidad de la Rehabilitación Integrada en sus inicios, fue perdiendo peso paulatino desde mediados de los ochenta y fundamentalmente en la década de los noventa de la mano del debilitamiento del planeamiento y el refuerzo del neoliberalismo. Ya en los dos mil, tanto la creciente preocupación por la accesibilidad, la movilidad y los temas ambientales, como la situación real de barrios que, excluidos hasta entonces de la ciudad, empezaban a visibilizarse como un problema urgente, hizo recuperar esta integración desde otro punto de vista. A pesar de dicha recuperación, no se pueden considerar equivalentes la integración en la ciudad de una y otra época.

\subsection{La evolución de los parámetros del enfoque integrado}

Aunque el enfoque integrado como tal, no apareció en el marco internacional hasta los años noventa, las propuestas y referencias a los parámetros vinculados a éste (integración en la ciudad, de las áreas y de los agentes), han tenido presencia en el discurso de las políticas que se engloban bajo el paraguas de la regeneración y rehabilitación urbana desde sus orígenes.

Estos factores, de base económica y política, pero también social y física, se han vinculado en cada momento con un tipo de intervención sobre la realidad existente, inseparable del modelo de ciudad propuesto en cada época. Estos modelos y la transición entre ellos han marcado, a rasgos generales, la evolución entre los parámetros estudiados.

De un lado, el planteamiento inicial de la Rehabilitación Integrada, caracterizada en la teoría y el discurso internacional por un alto grado de integración en todos sus parámetros, que no llegó, sin embargo, a asumir- 
GAPP. Nueva Época - N. ${ }^{\circ}$ 20, noviembre 2018 - ISSN: 1989-8991 - DOI: 10.24965/gapp.v0i20.10488 - [Págs. 82-99]

Número monográfico - Gobernanza y políticas de desarrollo urbano: teoría y práctica

Evolución de los parámetros del enfoque integrado en las políticas de regeneración urbana en los barrios vulnerables en España Ángela Matesanz Parellada / Agustín Hernández Aja

se de igual manera e intensidad en el discurso institucional estatal. En él la Rehabilitación Integrada terminó caracterizándose por su perfil sectorial (intervención en la vivienda), por la limitación de la integración de los agentes a la coordinación interadministrativa y por una cada vez menor integración en el planeamiento.

Del otro lado, la ciudad neoliberal de la Regeneración urbana y el desarrollo sostenible, que tomó la integración como bandera, aunque con planteamientos ideológica y materialmente muy diferentes a los de la anterior, y que se sumó en el caso español a la al discurso y práctica ya existente apoyados en el modelo sectorial de intervención.

Entre un modelo y otro, la consolidación de la Rehabilitación Urbana como práctica sectorial, poco integrada en todos los parámetros en el discurso, que, sin embargo, en la práctica ante las necesidades de muchos barrios ha buscado una mayor articulación a todos los niveles.

\section{REFERENCIAS BIBLIOGRÁFICAS}

ÁLVAREZ MORA, A. (1995). Conservación del patrimonio, restauración arquitectónica y recomposición elitista de los espacios urbanos históricos: Lección de apertura del curso académico 1995-96. Valladolid: Universidad de Valladolid.

AMANN, E. (1983). "Rehabilitación urbana en España", en Algunos estudios básicos de rehabilitación en España. Madrid: Tecniberia. ISBN: 84-398-0281-1.

ATKINSON, R., HELD, G. y JEFFARES, S. (2010). "Theories of Discourse and Narrative: what do they mean for governance and policy?”, en ATKINSON, R., GEORGIOS, T. y ZIMMERMANN, K. (eds.) (2010). Sustainability in European Environmental Policy: Challenges of Governance and Knowledge, págs. 115-130. Reino Unido: Routledge.

BLANCO, I.; SUBIRATS, J. (2012). "Políticas urbanas en España: dinámicas de transformación y retos ante la crisis", en Geopolítica(s), vol. 3, núm. 1: 15-33. ISSN: 2172-3958.

BOHIGAS, O. (1985). Reconstrucción de Barcelona. Barcelona: Edicions 62. ISBN: 84-297-2213-0.

COMUNIDAD ECONÓMICA EUROPEA, CEE (1996). Informe sobre ciudades europeas sostenibles. Comisión Europea. Grupo de Expertos sobre Medio Ambiente Urbano. Dirección General XI, Medio Ambiente, Seguridad Nuclear y Protección Civil. Bruselas, marzo de 1996. ES/11/96/01490100.P00 (EN).

CARPINTERO, Ó. (dir.) (2015). El metabolismo económico regional español, Madrid: FUHEM Ecosocial.

CASTRILLO, M. A. (2013). "La réhabilitation urbaine: une politique impossible? ", en COUDROY DE LILLE, L.; VAZ, C.; VORMS, CH. (dir.) (2013). L'urbanisme espagnol depuis les années 1970. La ville, la démocratie et le marché: 113-125. Rennes: Presses Universitaires de Rennes, Collection Espace et Territoires.

CERVELLATI, P. L.; SCANNAVINI, R. (1973). Bologna: politica e metodologia del restauro nei centri storici. Ed. II Mulino. Bolonia. Edición empleada: (1976). Bolonia. Política y metodología de la restauración de centros históricos. Gustavo Gili. Barcelona. ISBN: 84-252-0882-3.

DE GREgoRIO, S. (2012). Políticas Urbanas de la Unión Europea desde la Perspectiva de la planificación colaborativa. Las iniciativas URBAN I y URBAN II en España. SÁNCHEZ DE MADARIAGA, I. (dir.), Universidad Politécnica de Madrid, Madrid.

GARCÍA GARCÍA, M. ${ }^{a}$ J. (1999). El régimen jurídico de la rehabilitación urbana. Valencia: Institució Alfons el Magnànim.

Gobierno de España (1978). "Constitución Española”. Cortes Generales. BOE, núm. 311, 29-12-1978: 29.313-29.424.

GONZÁLEZ MEDINA, M. (2011). "Elementos de una política urbana europea. Experiencias de gestión del desarrollo urbano en Alemania y España”, en Revista Española de Ciencia Política (27): 45-67, 53 Ref. ISSN: 1575-6548.

HERNÁNDEZ AJA, A., García Madruga, C.; RODRíguEZ SUÁREZ, I.; MATESANZ PARELLADA, Á. (2014). Políticas estatales en áreas de rehabilitación integral, tipología urbana y vulnerabilidad social. En: ACE: Architecture, City and Environment = Arquitectura, Ciudad y Entorno, 9 (26): 127-146, 2014. DOI: http://dx.doi. org/10.5821/ace.9.26.3686. ISSN: 1886-4805.

JACQUIER, C. (1991). Voyage dans dix quartiers européens en crise. Objectif ville. Paris: L'Hartmann.

LÓPEZ, J., TOSICS, I. (2010). Nodus, Final outputs, mayo 2010. Disponible en: http://urbact.eu/sites/default/files/ import/Projects/NODUS/outputs_media/NODUS_Final_Report_def_01.pdf.

MANZANO, V. (2005). Introducción al análisis del discurso. Material de docencia. Disponible en: http://www.aloj.us.es/ vmanzano/docencia/metodos/discurso.pdf.

MATESANZ, Á. (2017). Políticas urbanas y vulnerabilidad. Tesis Doctoral. Madrid 7 de febrero de 2017. Universidad Politécnica de Madrid. DOI: https://doi.org/10.20868/upm.thesis.44893.

MATESANZ, Á. y CASTRILLO, M. A. (2015). "Urban regeneration policies: notes on the translation of European discourse in Spain". En el panel Urban regeneration policies in Europe: Theory and practice, celebrado en 3 de julio de 2015 en el marco del International Conference on Public Policy, organizado por la International Public Policy Association, del 1 al 4 de julio de 2015, 3 de julio de 2015. Università Cattolica del Sacro Cuore. Milán.

MATESANZ, Á. y HERNÁNDEZ, A. (2016). "La rehabilitación urbana como integración en la ciudad: Modelo de análisis desde la experiencia española”, en Revista ARQUIS 10, vol. 5, núm. 2 (2016). Universidad de Costa Rica - Escuela de Arquitectura. Costa Rica. DOI: https://doi.org/10.15517/ra.v5i2.27138. 
GAPP. Nueva Época - N. ${ }^{\circ}$ 20, noviembre 2018 - ISSN: 1989-8991 - DOI: 10.24965/gapp.v0i20.10488 - [Págs. 82-99]

Número monográfico - Gobernanza y políticas de desarrollo urbano: teoría y práctica

Evolución de los parámetros del enfoque integrado en las políticas de regeneración urbana en los barrios vulnerables en España Ángela Matesanz Parellada / Agustín Hernández Aja

MATESANZ, Á. y HERNÁNDEZ, A. (2014). "On the improvement of urban regeneration processes from more than thirty years of rehabilitation experiences", en World Sustainable Building Conference 2014, 28 a 30 de octubre de 2014, Barcelona, España.

MARTÍ-COSTA, M.; BLANCO, I.; PARÉS, M. (2009). "Barris, exclusió social i polítiques de regeneració", En MARTíCOSTA, M.; PARÉS, M. (coord.). 2009. Llei de Barris. Generalitat de Catalunya. ISBN: 978-84-393-8109-9.

MERINERO, R.; HUETE, M. A. y MUÑOZ, R. (2013). "Políticas de regeneración urbana en España: la dimensión sustantiva y procedimental. Del contenido de las políticas a la gobernanza", en Gestión y Análisis de Políticas Públicas, Nueva Época, núm. 9, enero-junio 2013. ISSN: 1989-8991. DOI: https://doi.org/10.24965/gapp. v0i9.10085.

MINISTERIO DE OBRAS PÚBLICAS Y URBANISMO (MOPU). (1981). Rehabilitación urbana: programa de operaciones piloto de actuación conjunta en áreas urbanas y asentamientos rurales. Madrid: Dirección General de Acción Territorial y Urbanismo.

MOLINA COSTA, P. (2007). "Análisis de los instrumentos de intervención urbanística en suelo urbano", en Boletín $C F+S, 51: 63-93$ (2012).

ORGANIZACIÓN PARA LA COOPERACIÓN Y EL DESARROLLO ECONÓMICO, OCDE. (1978). For better urban living. OCDE Group on urban environment. París: OECD Publishing.

ORGANIZACIÓN PARA LA COOPERACIÓN Y EL DESARROLLO ECONÓMICO, OCDE (1994). "Les nouvelles orientations de la politique social”. Études de politique sociale, núm. 12. OECD Publishing. París. ISBN: 92-6424056.

POL MÉNDEZ, F. (2006). Notas sobre los antecedentes de la urbanística de la recuperación de centros históricos. Asamblea ciudadana del Barrio de Universidad (ACIBU), disponible en: http://www.acibu.com/wp-content/ uploads/2008/06/fpantecedentes-1.pdf.

RUBIO DEL VAL, J. (2011). "Rehabilitación Urbana en España (1989-2010). Barreras actuales y sugerencias para su eliminación”, en Informes de la Construcción, vol. 63, Extra, 5/20-10-2011, ISSN: 0020-0883, elSSN: 1988-3234.

RUBIO DEL VAL, J. (dir.) (1990). La política de rehabilitación urbana en España. Evolución, experiencias y efectos Ministerio de Obras Públicas y Urbanismo. Madrid.

TERÁN TROYANO, F. de (1984). "Teoría e intervención en la ciudad, balance de un periodo. Estado de la cuestión. Perspectivas". Conferencia en ciclo organizado por la Fundación de Investigaciones Marxistas, 12-03-1984, en Ciudad y Territorio. núm. 59-60, enero-junio 1984: 61-68, Madrid: Ministerio de Fomento.

VAN DIJK, T. A. (2005). "Ideología y análisis del discurso". Utopia y Praxis Latinoamericana, vol. 10, núm. 29, Maracaibo, junio 2005.

UE (2016). "Pobreza urbana”. Agenda Urbana Europea. Disponible en: https://ec.europa.eu/futurium/en/node/1954.

\section{Legislación estatal analizada}

- "Real Decreto 1346/1976, de 9 de abril, por el que se aprueba el texto refundido de la ley sobre régimen del suelo y ordenación urbana" (RD 1346/1976). Ministerio de Vivienda, BOE, núm. 144, 16-06-1976: 11.755-11.769.

- "Real Decreto 2159/1978, de 23 de junio, por el que se aprueba el Reglamento de Planeamiento para el desarrollo y aplicación de la Ley sobre Régimen del Suelo y Ordenación Urbana" (RD 2159/1978). Ministerio de Obras Públicas y Urbanismo. BOE, núm. 221, 15-09-1978, págs. 21.592-21.606.

- "Real Decreto Ley 12/1980, para impulsar las actuaciones del estado en materia de vivienda y suelo" (RDL 12/1980). Jefatura de Estado. BOE, núm. 238, 3-10-1980.

- "Real Decreto 2555/1982 por el que se arbitran medidas para la rehabilitación integrada del patrimonio arquitectónico en centros urbanos, núcleos rurales y conjuntos histórico-artísticos" (RD 2555/1982). Presidencia del Gobierno. BOE, núm. 243, 11-10-1982, págs. 28.042-28.043.

- "Real Decreto 2329/1983, de 28 de julio, sobre protección a la rehabilitación del patrimonio residencial y urbano" (RD 2329/1983). BOE, núm. 214, 7-09-1983: 24.673-24.678.

— "Real Decreto 2329/1983, de 28 de julio, sobre protección a la rehabilitación del patrimonio residencial y urbano" (RD 3280/1983). Presidencia del Gobierno. BOE, núm. 214, de 7-9-1983, págs. 24.673-24.678.

- "Ley 16/1985, de 25 de junio, del Patrimonio Histórico Español" (L 16/1985). Jefatura del Estado. BOE, núm. 155, 29-6-1985, págs. 20.342-20.352.

- "Real Decreto 1494/1987, de 4 de diciembre, sobe medidas de financiación de actuaciones protegibles en materia de vivienda" (RD 1494/1987). Ministerio de Obras Públicas y Urbanismo. BOE, núm. 297, 12-12-1987, págs. 36.544-36.551.

- "Real Decreto 224/1989, de 3 de marzo, sobre medidas de financiación de actuaciones protegibles en materia de vivienda" (RD 224/1989). Ministerio de Obras Públicas y Urbanismo. BOE, núm. 57, 8-3-1989, págs. 6.506-6.514.

— "Ley 8/1990, sobre Reforma del Régimen Urbanístico y Valoraciones del Suelo".

- "Real Decreto Legislativo 1/1992, por en el que se aprueba el texto refundido de la ley sobre el régimen del suelo y ordenación urbana" (RDL 1/1992). Ministerio de Obras Públicas y Transportes. BOE, núm. 156, 30-06-1992: 22.238-22.274. 
GAPP. Nueva Época - N. ${ }^{\circ}$ 20, noviembre 2018 - ISSN: 1989-8991 - DOI: 10.24965/gapp.v0i20.10488 - [Págs. 82-99]

Número monográfico - Gobernanza y políticas de desarrollo urbano: teoría y práctica

Evolución de los parámetros del enfoque integrado en las políticas de regeneración urbana en los barrios vulnerables en España Ángela Matesanz Parellada / Agustín Hernández Aja

- "Real Decreto 1932/1991, sobre medidas de financiación de actuaciones protegibles en materia de vivienda del plan 1992-1995" (RD 1932/1991). Ministerio de Obras Públicas y Transportes. BOE, núm. 12, 14-1-1992, págs. 987-997.

- "Real Decreto 726/1993, de 14 de mayo, por el que se regula la financiación de actuaciones protegibles en materia de rehabilitación de inmuebles y se modifican determinados artículos del Real Decreto 1932/1991, 20-12-1991" (RD 726/1993). Ministerio de Obras Públicas y Transportes. BOE, núm. 139, 11-06-1993, págs. 17.888-17.894.

- "Real Decreto 2190/1995 sobre medidas de financiación de actuaciones protegibles en materia de vivienda y suelo para el periodo 1996-1999" (RD 2190/1995). Ministerio de Obras Públicas, Transportes y Medio Ambiente. BOE, núm. 312, 30-12-1995.

- "Ley 6/1998, de 13 de abril, sobre régimen del suelo y valoraciones" (L 6/1998). Jefatura del Estado. BOE, núm. 89, 14-04-1998, págs.12.296-12.304.

- "Real Decreto 1186/1998, sobre medidas de financiación de actuaciones protegidas en materia de vivienda y suelo del plan 1998-2001" (RD 1186/1998). Ministerio de Fomento. BOE, núm. 152, 26-6-1998.

- "Real Decreto 1/2002 sobre medidas de financiación de actuaciones protegidas en materia de vivienda y suelo del Plan 2002-2005" (RD 1/2002). Ministerio de Fomento. BOE, núm. 11, 12-1-2002.

_ "Real Decreto 801/2005 por el que se aprueba el Plan Estatal 2005-2008, para favorecer el acceso de los ciudadanos a la vivienda Ministerio de Vivienda" (RD 801/2005). BOE, núm. 166, 13-7-2005.

- Estrategia Española de Medio Ambiente Urbano (EEMAU 2006). Ministerio de Medio Ambiente, Red de Redes de Desarrollo Local Sostenible (2006). Ministerio de Medio ambiente. Centro de publicaciones Secretaría General Técnica.

- Marco Estratégico Nacional de Referencia de España 2007. Ministerio de Hacienda (2007), 27 de abril de 2007.

- Resolución de 7 de noviembre de 2007, de la Secretaría de Estado de Cooperación Territorial por la que se aprueban las bases reguladoras de la convocatoria 2007 de ayudas del Fondo Europeo de Desarrollo Regional para cofinanciar proyectos de desarrollo local y urbano durante el periodo de intervención 2007-2013.

- "Ley 8/2007, de 28 de mayo, de suelo". Jefatura del Estado. BOE, núm. 128, 29-05-2007: 23.266-23.284.

- "Real Decreto 14/2008, de 11 de enero, por el que se modifica el Real Decreto 801/2005, de 1 de julio, por el que se aprueba el Plan Estatal 2005-2008, para favorecer el acceso de los ciudadanos a la vivienda" (RD 14/2008). Ministerio de Vivienda. BOE, núm. 11, 12-1-2008, págs. 2.301-2.310.

- "Real Decreto 2066/2008, de 12 de diciembre, por el que se regula el Plan Estatal de Vivienda y Rehabilitación 2009-2012" (RD 2066/2008). Ministerio de Vivienda. BOE, núm. 309, 24-12-2008, págs. 51.909-51.937.

- "Ley 2/2011, de 4 de marzo, de Economía Sostenible". Jefatura del Estado. BOE, núm. 55, 5-03-2011: 25.03325.235.

- "Ley 8/2013, de 26 de junio, de rehabilitación, regeneración y renovación urbanas. Jefatura del Estado”. BOE, núm. 153, 27-06-2013, págs. 47.964-48.023.

\section{Documentos internacionales analizados}

CONSEJO DE EUROPA (CdE) (1975a). Carta europea del patrimonio arquitectónico. Comité de Ministros. Ámsterdam, 26-09-1975.

CONSEJO DE EUROPA (CdE) (1975b). Declaración de Ámsterdam. Congreso sobre el patrimonio arquitectónico europeo. Ámsterdam, 21/25-10-1975.

ORGANIZACIÓN DE LAS NACIONES UNIDAS (ONU) (1976a). Declaración sobre los asentamientos humanos. Conferencia de las Naciones Unidas sobre Asentamientos Humanos (Hábitat I), Vancouver, 11-6-1976 / 31.

CONSEJO DE EUROPA (CdE) (1982). Conclusiones de la Conferencia de Berlín. Anexo VII. Berlín Oeste, 8/12-051982.

CONSEJO DE EUROPA (CdE) (1983). Carta europea de la ordenación del territorio. $6 .{ }^{\circ}$ Conferencia Europea de Ministros Responsables de la Ordenación del Territorio (CEMAT). Torremolinos, 20-05-1983.

CONSEJO DE EUROPA (CdE) (1985). Convenio para la salvaguarda del patrimonio arquitectónico de Europa (Carta de Granada). Granada, 3-10-1985.

Comisión Europea. Proyecto Piloto Urbanos (1989), a través de Unión Europea (UE) (1998b). Article 10 of the European Regional Development Fund. Urban Pilot Projects Annual Report 1996. Directorate General for Regional Policy and Cohesion of the European Commission. Luxembourg: Office for Official Publications of the European Communities.

COMUNIDAD ECONÓMICA EUROPEA (CEE) (1990). Libro Verde del Medio Ambiente Urbano. Comisión de Comunidades Europeas. Comunicación (1990), 218 Final, 26-07-1990. COM (90) 218.

CONSEJO DE EUROPA (CdE) (1992a). Carta urbana europea y Declaración europea sobre el derecho a la ciudad. Resolución 234 (1992) de la Conferencia Permanente de Poderes Locales y Regionales de Europa.

CONSEJO DE EUROPA (CdE) (1992b). 3. ${ }^{a}$ Conferencia europea de Ministros responsables del patrimonio cultural. Malta, 16/17-01-1992. Declaración final y Resoluciones.

ORGANIZACIÓN DE LAS NACIONES UNIDAS (ONU) (1992a). Informe de la Conferencia de las Naciones Unidas sobre el Medio Ambiente y el Desarrollo. Conferencia de las Naciones Unidas sobre el Medio Ambiente y el 
GAPP. Nueva Época - N. ${ }^{\circ}$ 20, noviembre 2018 - ISSN: 1989-8991 - DOI: 10.24965/gapp.v0i20.10488 - [Págs. 82-99]

Número monográfico - Gobernanza y políticas de desarrollo urbano: teoría y práctica

Evolución de los parámetros del enfoque integrado en las políticas de regeneración urbana en los barrios vulnerables en España Ángela Matesanz Parellada / Agustín Hernández Aja

Desarrollo. Río de Janeiro, 3/14-6-1992. Ed. Naciones Unidas, vol. I: Resoluciones aprobadas por la Conferencia, resolución 1 , anexo II.

UNIÓN EUROPEA (UE) (1994b). Comunicación de los Estados Miembros, se fijan las orientaciones para los programas operativos que se invita a elaborar dentro de la iniciativa comunitaria de zonas urbanas (Programa Urban) 94/c180/02,15-06-94.

CONSEJO DE EUROPA (CdE) (1996a). $4 .^{\circ}$ Conferencia europea de Ministros responsables del patrimonio cultural. Helsinki, 30 y 31-05-1996. Declaración final y Resoluciones.

CONSEJO DE EUROPA (CdE) (1996b). Carta social europea revisada. Estrasburgo, 3-05-1996.

ORGANIZACIÓN DE LAS NACIONES UNIDAS (ONU) (1996a). Declaración de Estambul sobre los Asentamientos Humanos. Conferencia de las Naciones Unidas sobre los Asentamientos Humanos, Estambul, Turquía, 3/14-6-1996.

UNIÓN EUROPEA (UE) (1997). Hacia una política urbana para la Unión Europea. Comisión Europea, CE. Comunicación para la comisión, COM (97) 197, final 06-05-1997, Bruselas.

UNIÓN EUROPEA (UE) (1998a). Marco de Actuación para el Desarrollo Urbano Sostenible en la Unión Europea. Comisión Europea. Comunicación de la Comisión al Consejo, al Parlamento Europeo, al Comité Económico y Social y al Comité de las Regiones. Bruselas, 28-10-98 COM (1998) 605.

CONSEJO DE EUROPA (CdE) (2000f). Principios directores para el desarrollo territorial sostenible en el continente europeo. $12 .^{\circ}$ CEMAT. Hanover, 7/8-9-2000.

UNIÓN EUROPEA (UE) (2000e). Agenda Social Europea. Comisión Europea. Consejo Europeo de Niza de 7, 8 y 9-122000 (2001/C 157/02). C 157/4 ES, Diario Oficial de las Comunidades Europeas 30-5-2001.

UNIÓN EUROPEA (UE) (2000b). Programa de Acción de Lille. Comisión Europea. Conclusions of the French Presidency of the European Union at the end of the informal meeting of Ministers responsible for urban affairs. Lille, 2-11-2000

UNIÓN EUROPEA (UE) (2000d). Dictamen del Comité Económico y Social sobre la «Comunicación de la Comisión a los Estados miembros por la que se fijan las orientaciones de una iniciativa comunitaria relativa a la regeneración económica y social de las ciudades y de los barrios en crisis con el fin de fomentar un desarrollo urbano sostenible - Urban». Comisión Europea.

ORGANIZACIÓN DE LAS NACIONES UNIDAS (ONU) (2001). Declaración sobre las ciudades y otros asentamientos humanos en el nuevo milenio. Asamblea General de Naciones Unidas, Nueva York (Estados Unidos), 9-06-2001

ORGANIZACIÓN DE LAS NACIONES UNIDAS (ONU) (2001). Cumbre Desarrollo Sostenible.

UNIÓN EUROPEA (UE) (2004b). Urban Acquis. Comisión Europea. Ministerial meeting Urban Policy 'Cities Empower Europe Conclusions Dutch Presidency 2004. Ministry of Interior and Kingdom Relations, The Netherlands, 13-012005.

CONSEJO DE EUROPA (CdE) (2004). Estrategia de Cohesión social. A new strategy for Social Cohesion. Revised strategy for Social Cohesion. Comité de Ministros del Consejo de Europa. 31 de marzo de 2004. Comité Europeo para la Cohesión Social.

UNIÓN EUROPEA (UE) (2005a). Conclusions of Bristol Ministerial Informal Meeting on Sustenaible Communities in Europe. Comisión Europea. Presidencia del Reino Unido, Bristol, 6-7.12. Publicado en 03.2006 Office of the Deputy Prime Minister: London.

UNIÓN EUROPEA (UE) (2005). Estrategia temática para el medio ambiente urbano. Comisión Europea. Comunicación de la Comisión Europea al Consejo y al Parlamento Europeo, COM (2005), 718 final, Bruselas.

UNIÓN EUROPEA (UE) (2006). Estrategia Revisada para un Desarrollo Sostenible. Consejo de la Unión Europea. Bruselas, 9-06-2006 (OR. en).

UNIÓN EUROPEA (UE) (2007). Carta de Leipzig. Consejo de Ministros. Acordada con ocasión de la reunión informal de ministros sobre desarrollo urbano y cohesión territorial en Leipzig, 24/25-05-2007.

UNIÓN EUROPEA (UE) (2008). Declaración de Marsella. Reunión Informal de Ministros de Desarrollo Urbano de la UE, celebrada en Marsella el 25 de noviembre de 2008. Consejo de Ministros. Resolución sobre el seguimiento de la Agenda Territorial de la UE y de la Carta de Leipzig, A6 0028/2008.

CONSEJO DE EUROPA (CdE) (2008). Carta de los Derechos Urbanos. Manifesto for a new urbanity. European Urban Charter II, Estrasburgo. 29-05-2008.

UNIÓN EUROPEA (UE) (2008a). Libro Verde sobre la cohesión territorial: Convertir la diversidad territorial en un punto fuerte. Comisión Europea. Comunicación de la comisión al consejo, al parlamento europeo, al comité de las regiones, al comité económico y social europeo. Bruselas, 6-10-2008. COM (2008) 616 final.

UNIÓN EUROPEA (UE) (2010). Declaración de Toledo. Ministros encargados del desarrollo Urbano. Consejo de Ministros de la Unión Europea. Toledo. 22-07-2010. 